\title{
Open but Not for All: A Survey of Open Educational Resource Librarians on Accessibility
}

\section{Teresa Auch Schultz and Elena Azadbakht}

\begin{abstract}
This project sought to study how much academic librarians who work with open educational resources (OERs) know about accessibility, as well as how they incorporate accessibility into the products of their work. A survey was sent out through email list services in spring 2020, and any librarian worldwide who works with OERs was invited to participate; 193 responded in full. Just under half of librarians said they always consider accessibility when working with faculty to create or adapt OERs, but fewer than a third said they consider accessibility a factor when adding OERs to their collections.
\end{abstract}

\section{Introduction}

The growing open education movement seeks to democratize teaching and learning. As defined by Scholarly Publishing and Academic Resources Coalition (SPARC), open education is the set of "resources, tools, and practices that are free of legal, financial, and technical barriers." ${ }^{1}$ One cornerstone of the movement is open educational resources. These no-cost alternatives to the traditional textbooks used at many colleges and universities in the United States and beyond can take different forms, from e-books to online modules composed of several related readings and videos. They are also typically shared under Creative Commons licenses, allowing for remix and reuse by others. ${ }^{2}$ As key resource providers, many libraries and librarians lead or support initiatives at their institutions that encourage the creation, discovery, and adoption of OERs. Others have added OERs to their collections to make them more discoverable for faculty and students and encourage adoption.

Although the cost savings that OERs bring to students can be significant, several barriers to their widespread adoption exist. ${ }^{3}$ Creating, and even evaluating, OERs is an often timeintensive process, and many instructors and subject matter experts lack the resources and support needed to produce quality OERs. ${ }^{4}$ This lack may include the knowledge and tools vital to making open material accessible to learners with disabilities, which is mandated by the Section 508 amendment of the Rehabilitation Act of $1978 .{ }^{5}$ Librarians are not exempt from this requirement, especially as they increasingly work with faculty to create and adapt OERs and include them in their collections. Accessible OERs are not just a legal issue; if OER advocates, including librarians, continue to tout how OERs are for everyone, then they need to ensure that they are not just for people without a disability. Consequently, librarians who work with OERs

Teresa Auch Schultz is a Social Sciences Librarian and Elena Azadbakht is a Health Sciences Librarian, both at the University of Nevada, Reno; email: teresas@unr.edu, azadbakht@unr.edu. (02021 Teresa Auch Schultz and Elena Azadbakht, Attribution-NonCommercial (https://creativecommons.org/licenses/by-nc/4.0/) CC BY-NC. 
need to take accessibility into account. This article discusses the results of an online survey about accessibility taken by nearly 200 academic librarians who work with OERs in some capacity. The survey's aim was to better understand these librarians' perceived knowledge of accessibility, the accessibility practices they engage in (if any), and the partners, resources, and tools they rely on to ensure any OERs used at their institutions are accessible.

\section{Literature Review}

In this study, accessibility refers to the need for content, in its various forms, to be fully usable by individuals with a wide range of abilities, including those with visual, auditory, physical, and cognitive impairments. ${ }^{6}$ For example, online images must have descriptive alternative text that screen readers, a type of assistive technology used by those with visual impairments, can render audibly. Section 508 stipulates that electronic and information technology be accessible to those with disabilities. ${ }^{7}$ This ruling applies to institutions of higher education and their academic libraries. In fact, numerous colleges and universities have faced lawsuits over the inaccessibility of their online content. ${ }^{8}$ In practice, many developers, designers, and instructors rely on the World Wide Web Consortium's Web Content Accessibility Guidelines (WCAG) to ensure their content is compliant with Section 508. ${ }^{9}$ An updated version, WCAG 2.1, debuted in 2018 and consists of three tiers: A (least stringent), AA, and AAA (most stringent). However, as with OERs, there are several challenges involved. Ensuring that all public-facing online material is accessible requires extensive staff time and knowledge. ${ }^{10}$ Although there are several tools that help content creators build accessibility into their work and evaluate how accessible existing material is, they are not entirely reliable, often necessitating a second, manual check. ${ }^{11}$

Recent library and information science research on accessibility focuses on academic libraries' need to adequately serve students with disabilities and the challenges these students face when navigating online library spaces and resources. ${ }^{12}$ Other studies evaluate the accessibility of the library e-resources themselves, including databases. ${ }^{13}$ Rebeca Peacock and Amy Vecchione surveyed academic libraries in the northwestern United States about their accessibility policies and how accessibility figures into their collection development work, with particular attention paid to their handling of multimedia materials. Of the 16 participants (representing various institutions), 90 percent reported that accessibility impacted their acquisitions decision-making in some way, but only about 20 percent said that their library or institution had a policy document or written guidelines about accessibility in purchasing. ${ }^{14}$ Most participants also indicated that their institutions did not have room in their budgets to adequately support accessibility training and resources at the library. Only 40 percent said that they had participated in the accessibility training offered at their colleges and universities. Confusion over the library's role in campuswide accessibility initiatives and efforts, including whom to partner with, was also evident. ${ }^{15}$

A 2019 LYRASIS survey of 155 participants from across its more than 1,000 member institutions revealed that only 14 percent reported having a formal digital content acquisitions policy, and 24 percent said that their institution had an informal one. ${ }^{16} \mathrm{~A}$ third of respondents also said that they did not have an accessibility policy for content created by and for their institutions. Even fewer reported having a policy in place regarding the accessibility of the systems and tools they are considering adopting. ${ }^{17}$ However, respondents from institutions at which libraries undertake content creation reported having access to accessibility training more often than those who were not. Additionally, the researchers note that accessibility 
compliance, and the training needed to do it well, seems to be seen as the responsibility of each individual librarian. ${ }^{18}$

Proponents of open education have begun advocating for accessible OERs as well as developing best practices for creating and evaluating them. ${ }^{19}$ The literature also addresses the need for robust institutional support for faculty content creators. ${ }^{20}$ Other researchers have started evaluating the accessibility (and usability) of OER sites and platforms.

In 2015, Silvia Da Rosa and Regina Motz used the standards outlined in WCAG 2.0 (at Level AA) to evaluate a representative sample of open material from seven repositories in Argentina, Brazil, Colombia, Spain, and Uruguay. ${ }^{21}$ They also examined each repository's homepage. J. Puello, Y. Puerta, and L. Martínez likewise undertook a technical review of 30 Colombian universities' digital repositories using WCAG 2.0. ${ }^{22}$ The researchers identified 240 infractions, and only one repository conformed to the standards. This led them to conclude that accessibility was not a top priority for these universities when establishing a digital repository. ${ }^{23}$ Eulho Jung and colleagues used the COUP framework - a consideration of costs, outcomes, uses, and perceptions - to survey the OpenStax open textbook platform user base in their 2017 study. ${ }^{24}$

However, there has been little research done on how libraries and librarians approach accessibility in their work with OERs. This study seeks to help fill that gap by surveying selfidentified OER librarians about their accessibility efforts and recommend best practices for them.

\section{Research Questions}

1. How confident are OER librarians in their accessibility knowledge?

2. To what extent do OER librarians provide accessibility support (such as remediation assistance) to patrons?

3. To what extent do OER librarians evaluate the accessibility of OERs before adding them to their collections?

4. What other factors play a role in OER librarians providing accessibility support?

\section{Methodology}

This study used a four-part survey created in Qualtrics. The survey was partially created based on two prior surveys conducted on institutional repositories and accessibility, as they were the closest surveys to the topic of open and accessible and were adapted for OERs and the needs of this survey. ${ }^{25}$

The first section asked questions about the librarian's general duties involved with OERs, such as how much experience they have working with OERs, as well as what services they offer, to ascertain generally how much and what types of OER work the librarians performed. The second section focused on their general knowledge of accessibility, including what types of training they have, their confidence with accessibility, and whether their employer has any official policy. The goal of this section was to determine their general knowledge and awareness of accessibility practices. The third section, the focus of the survey, asked various questions about how they incorporated accessibility into their OER work. This section included questions about what types of accessibility services they offer for OERs, whom they collaborate with on accessibility, and what tools they use. The final section focused on demographic information on the types of institutions at which they work. 
Five librarians with a range of experience with OERs tested the survey for validity, and changes were made based on their responses. The University of Nevada, Reno Institutional Review Board approved the survey as exempt. The survey was initially sent on April 8, 2020, to three email discussion lists specifically targeting librarians interested in OERs: the Association of College \& Research Libraries' Scholarly Communication list, SPARC's Libraries and OER Forum, and the Creative Commons Open Education Platform. Anyone who identified as an academic librarian anywhere in the world and worked to any extent with OERs was asked to fill it out. Respondents were given until May 8 to complete it. Reminder emails were sent out on April 20, when the survey was also sent to two additional email discussion lists for two ACRL sections (Community and Junior College Libraries and Instruction). A final reminder was sent to all five email discussion lists on May 8.

A total of 283 people began the survey. Anyone who did not finish the survey and did not pass two screening questions was not included. That left 193 responses, although no question required an answer, and thus some questions had fewer responses. The vast majority of respondents (155) came from the United States, followed by Canada (11). The United Kingdom and Uganda tied for third (4), and Australia registered 3. Ghana, India, Ireland, and Zimbabwe each had one respondent. The authors do not consider this a representative sample. Most respondents also work at doctoral universities as defined by Carnegie Classification, followed by associate's colleges (see table 1). The size of institutions represented was fairly even across the board (see table 2)

\begin{tabular}{|l|c|c|}
\hline \multicolumn{3}{|c|}{ TABLE 1 } \\
\hline Respondents by Institution Type \\
\hline Institution Type & $\begin{array}{c}\text { No. of } \\
\text { Librarians }\end{array}$ & $\begin{array}{c}\% \text { of } \\
\text { Librarians }\end{array}$ \\
\hline Associate's college & 60 & $31 \%$ \\
\hline Baccalaureate college & 19 & $10 \%$ \\
\hline Master's college/university & 38 & $20 \%$ \\
\hline Doctoral university & 71 & $37 \%$ \\
\hline Special focus & 1 & $<1 \%$ \\
\hline Not classified & 1 & $<1 \%$ \\
\hline
\end{tabular}

\begin{tabular}{|l|c|c|}
\hline \multicolumn{3}{|c|}{ TABLE 2} \\
Respondents by Institution Size \\
\hline Institution Size & $\begin{array}{c}\text { No. of } \\
\text { Librarians }\end{array}$ & $\begin{array}{c}\text { \% of } \\
\text { Librarians }\end{array}$ \\
\hline Fewer than 2,500 & 37 & $19 \%$ \\
\hline 2,500 to 5,000 & 30 & $16 \%$ \\
\hline 5,001 to 10,000 & 41 & $21 \%$ \\
\hline 10,001 to 30,000 & 55 & $28 \%$ \\
\hline More than 30,000 & 29 & $15 \%$ \\
\hline
\end{tabular}

\section{TABLE 3}

How Many Librarians Offer Each Type of OER Service

\begin{tabular}{|l|c|c|}
\hline Service Offered & No. of Librarians & \% of Librarians \\
\hline Educate patrons about OER & 152 & $79 \%$ \\
\hline Copyright/Creative Commons help & 150 & $78 \%$ \\
\hline Consultations & 146 & $77 \%$ \\
\hline Workshops & 110 & $57 \%$ \\
\hline Participate on committee/task force & 100 & $52 \%$ \\
\hline Policy creation/administrative work & 76 & $39 \%$ \\
\hline Oversee incentive fund & 47 & $24 \%$ \\
\hline Publishing/review services (that is, copy editing, layout, and the like) & 33 & $17 \%$ \\
\hline
\end{tabular}




\section{Results}

\section{OER Experience}

Many librarians were still new to OERs, with 53 having worked with them for one year or less. Another 68 have worked with them for two or three years, while 44 had four to five years of experience, and just $28 \mathrm{had}$ more than five years of experience. More than two-thirds of the librarians (133) spent a quarter of their time or less working with OERs, while just 15 spent more than 75 percent of their work time with OERs. The most popular OER services included educating patrons about OERs, offering copyright help, and leading workshops (see table 3). A little more than half offer four services or fewer (101).

\section{Accessibility Knowledge}

Most librarians did report receiving some type of accessibility training, with just 18 saying they had none. While 54 librarians said they had taken only one type of training, 99 had taken two or three types of training, and 40 had taken three or more. The most common types of training on accessibility included webinars (126), workshops (111), and conference sessions (96) (see figure 1).

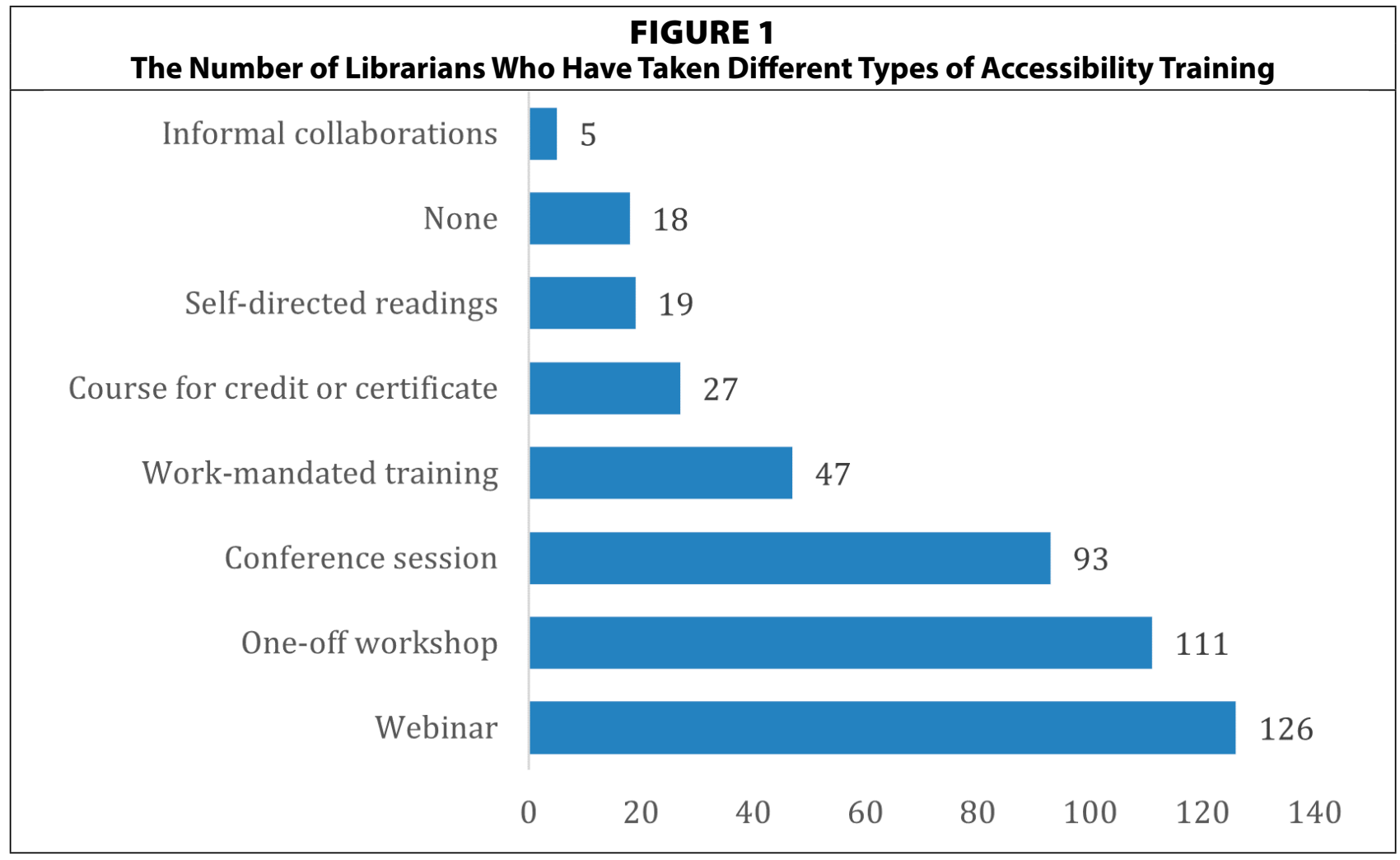

The survey defined the different levels of accessibility knowledge as:

- Not at all confident: I'm not aware of accessibility tools and practices at all.

- Somewhat confident: I'm aware of accessibility tools and practices but do not apply them.

- Confident: I'm somewhat familiar with the basics of accessibility tools and practices and apply them infrequently.

- Very confident: I'm familiar with accessibility tools and practices and apply them regularly. 
A majority of librarians (106) rated themselves as confident in their knowledge of accessibility, and just 11 librarians said they were not at all confident (see figure 2). All but 39 librarians said their institution and/or their library followed some kind of accessibility standard, with most (90) saying both did. The most common types of standards used by the institution and/or library to test for web accessibility were those specific to an institution, followed by Section 508 and WCAG 2.X AA (see figure 3).

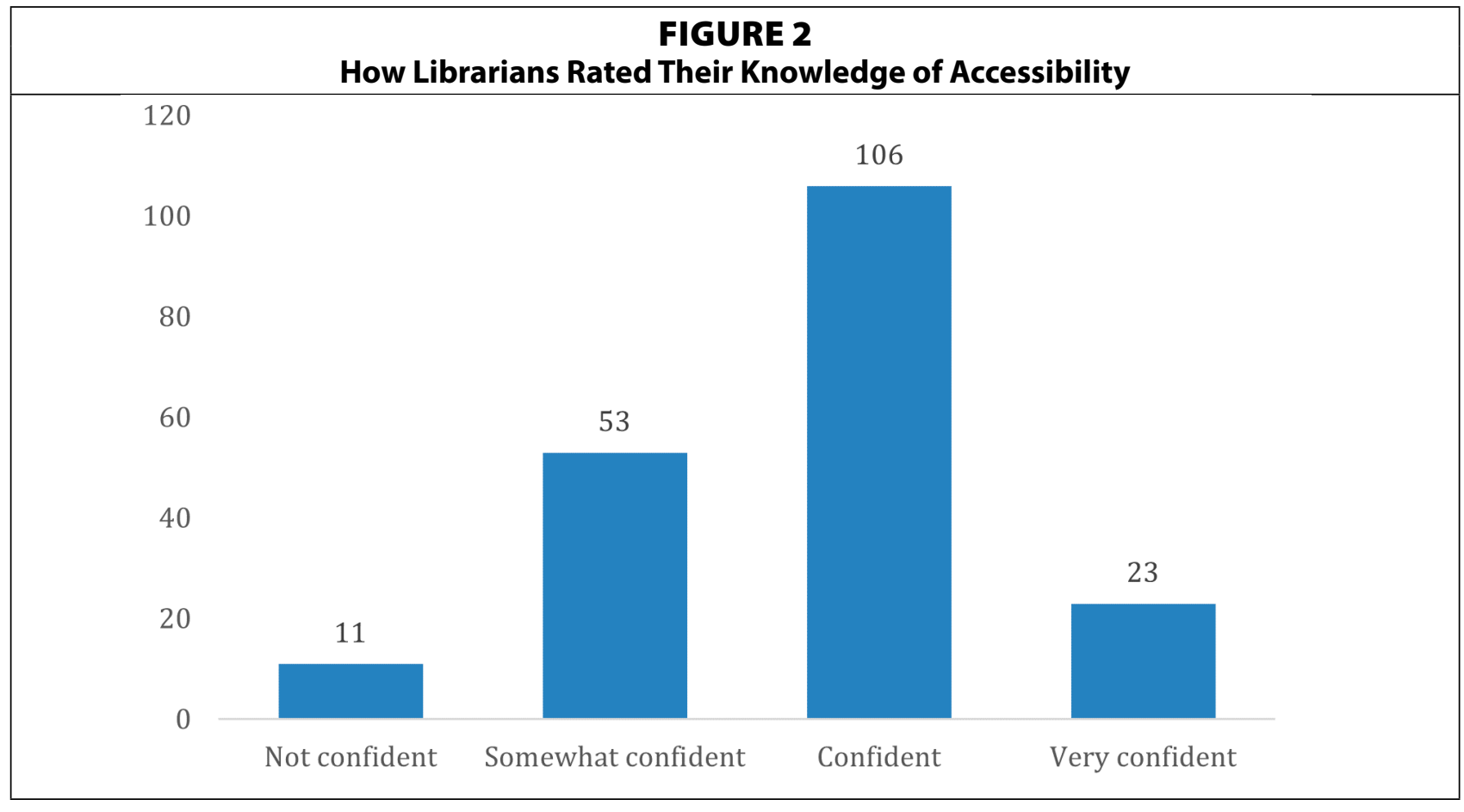

FIGURE 3

Types of Accessibility Standards Used by Respondent's Institution and/or Library for Web Accessibility Testing ( $\mathrm{N}=69)$

State/Territory specific

3

WCAG 2.X AAA

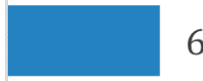

WCAG 2.X A

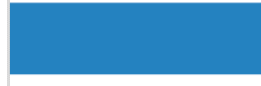

10

WCAG 2.X AA

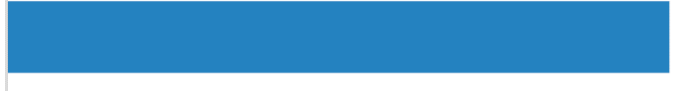

26

Section 508

28

Institutional

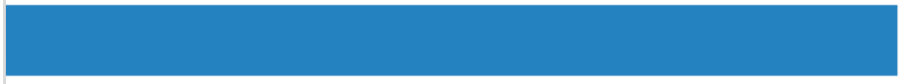




\section{OERs and Accessibility}

Just under half (91) of librarians said they do consider accessibility when helping instructors select and write OERs, and another 84 said they sometimes do, leaving 15 who said they do not. When broken down by institution type, the largest group of librarians to say they always consider accessibility came from associate's colleges (32). Although the second largest group to say they always do came from doctoral universities (29), that was the only institution type where more librarians said they sometimes consider accessibility (35) versus always. When comparing their answers to how confident they feel about accessibility, the results were mixed across the spectrum (see figure 4). In comparison to those who said they do offer OER publishing and review services, all but one said they always or sometimes consider accessibility. Finally, 10 of those who say their institution and/or library follows an accessibility standard say they do not consider accessibility when helping faculty with OERs, whereas the 33 librarians who say their workplace does not follow an accessibility standard say they do consider it when helping faculty with OERs.

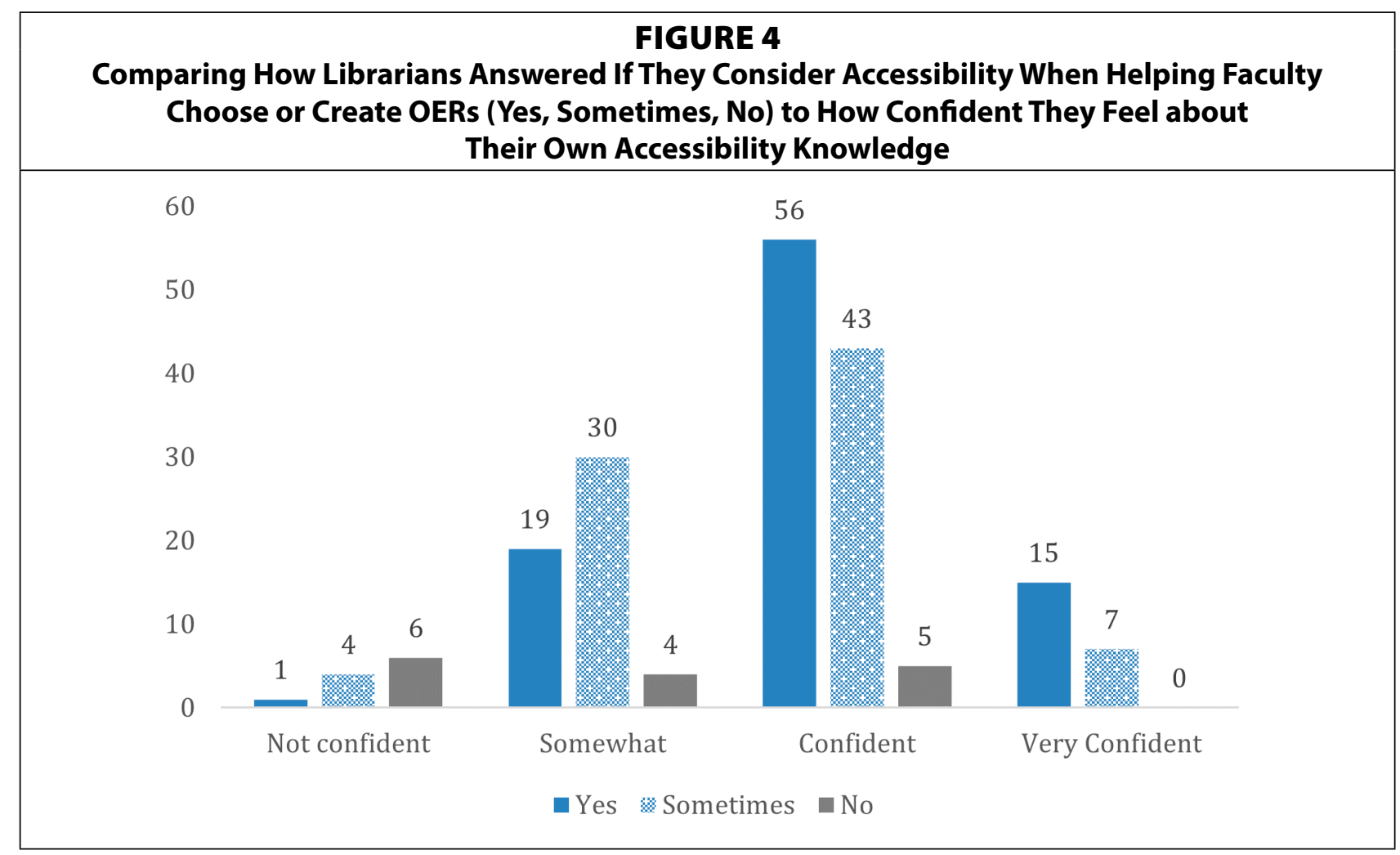

Just 54 said they consider accessibility when adding OERs to their library collection, compared to 74 who do not. Librarians from associate's colleges were the only ones who said they do (26) more than they do not (11) among the main institution types. Of those who provide publishing and review services for OERs, just eight say they consider accessibility when adding to collections, versus 14 who do not. When looking at those librarians who say their institution and/or library has an accessibility policy, 57 say they do not consider accessibility when adding OERs to their collection, versus nine who do despite having no accessibility policy.

All but 14 librarians provide some sort of accessibility information or support to instructors when it comes to OERs. The most common types offered are consultations (99), third-party 
resources (94), and referrals to other institutional personnel (77) (see figure 5). Of those who do offer actual remediation of OERs to make them accessible, working on alternative text for images was the most common service offered, followed by transcriptions and captions for video and audio (see figure 6).

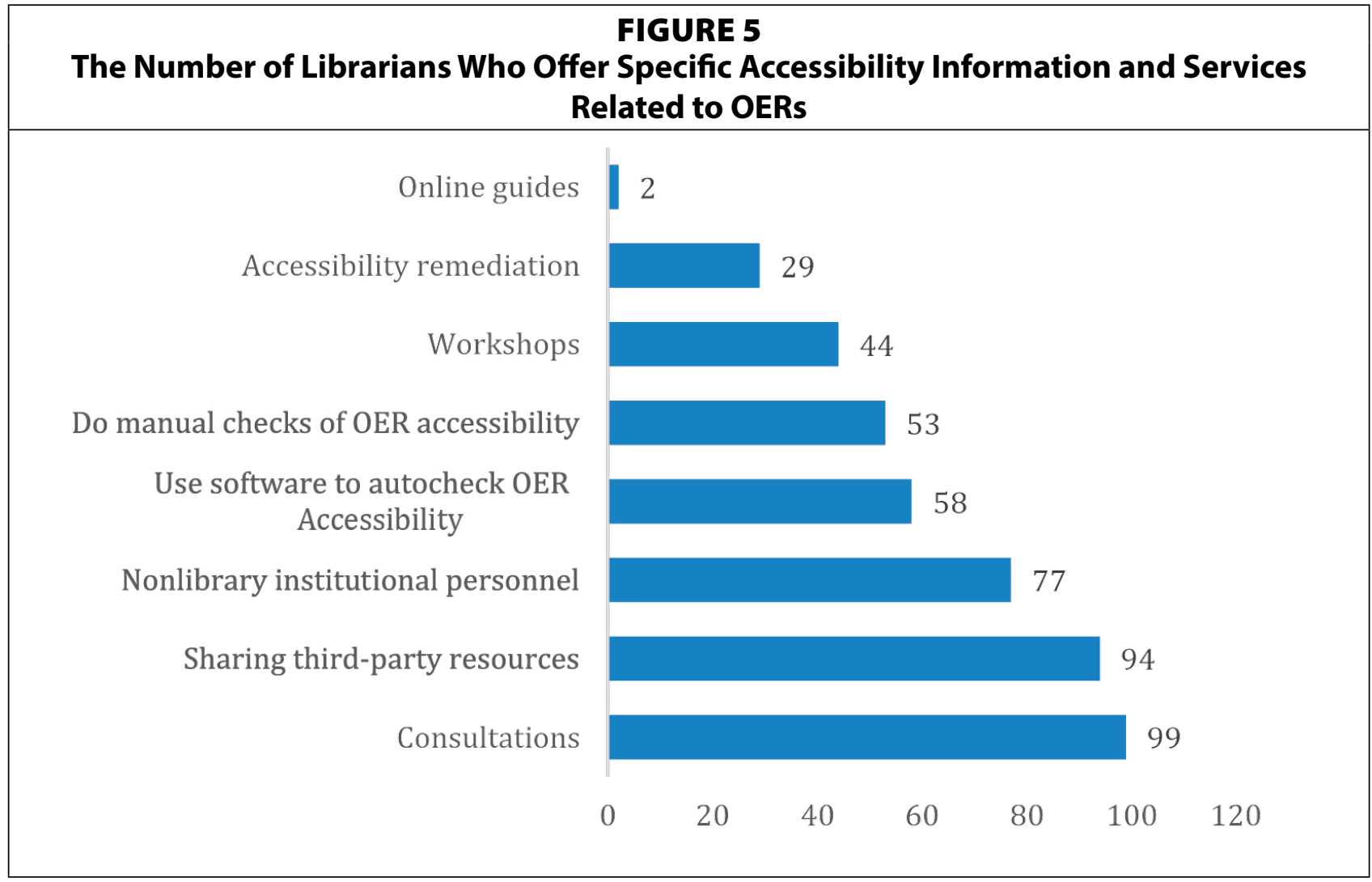

\section{FIGURE 6}

Number of Librarians Who Offer Specific Types of Accessibility Remediation of OERs ( $N=27)$

Enhanced metadata

Audio description

PDF editing (add tags, edit reading order, etc.)

Transcriptions

Captioning

Alternative text

0

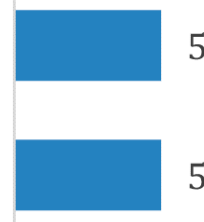

5

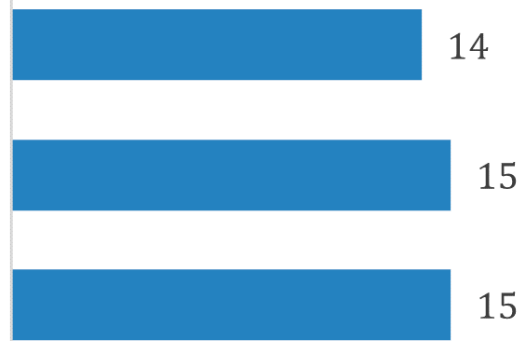

15

21 
The most common tools used for accessibility work include Microsoft Word (116) and Adobe Acrobat Pro (108), with more niche tools created specifically for accessibility, such as website checkers like Siteimprove and WAVE and EPUB file checkers like Ace by Daisy seeing much less use (see figure 7).

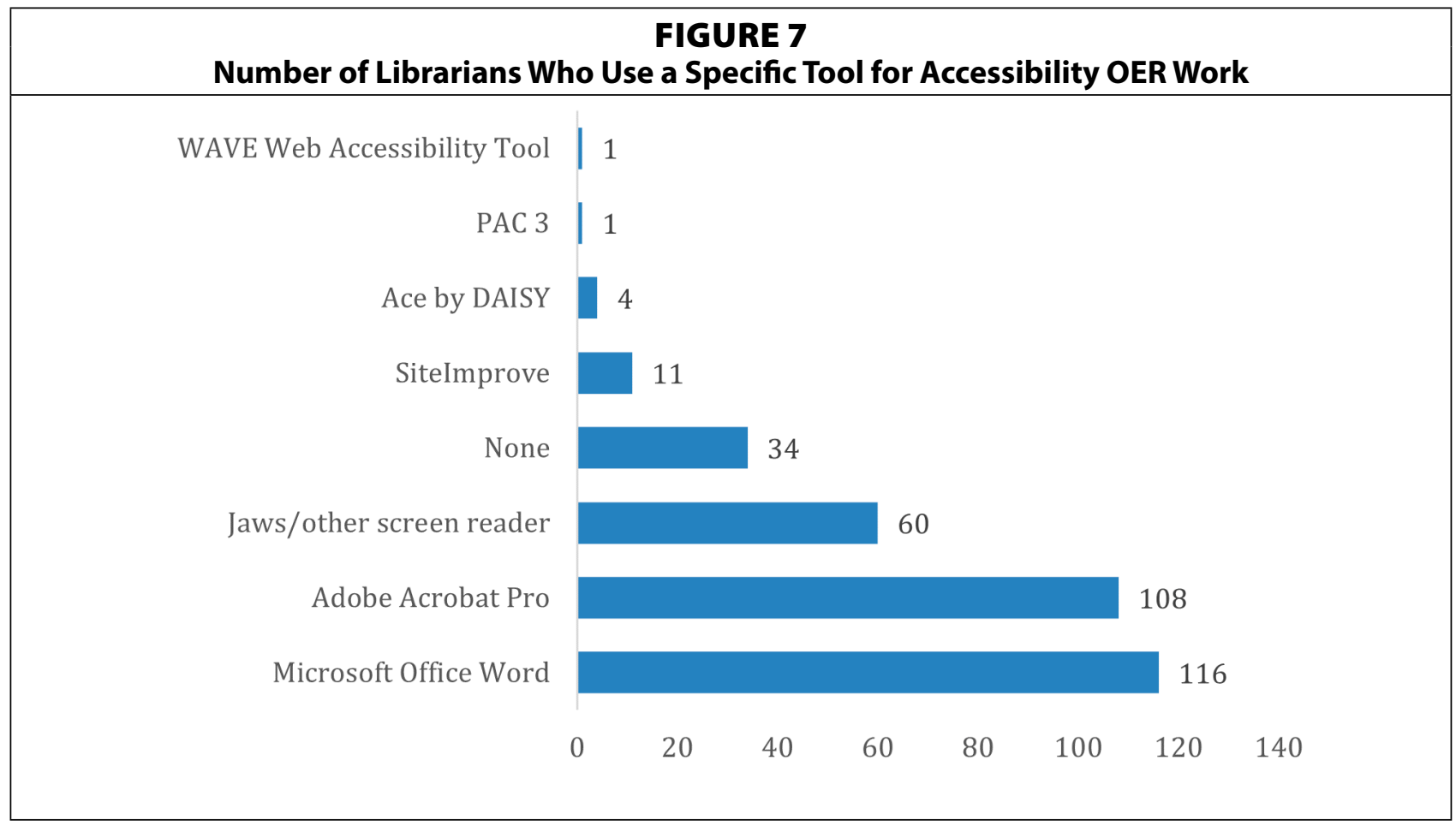

When it comes to seeking help from other university departments, the disability resource office was the most common place librarians made referrals to and collaborated with on accessibility, followed by instructional design and information technology (see figure 8).

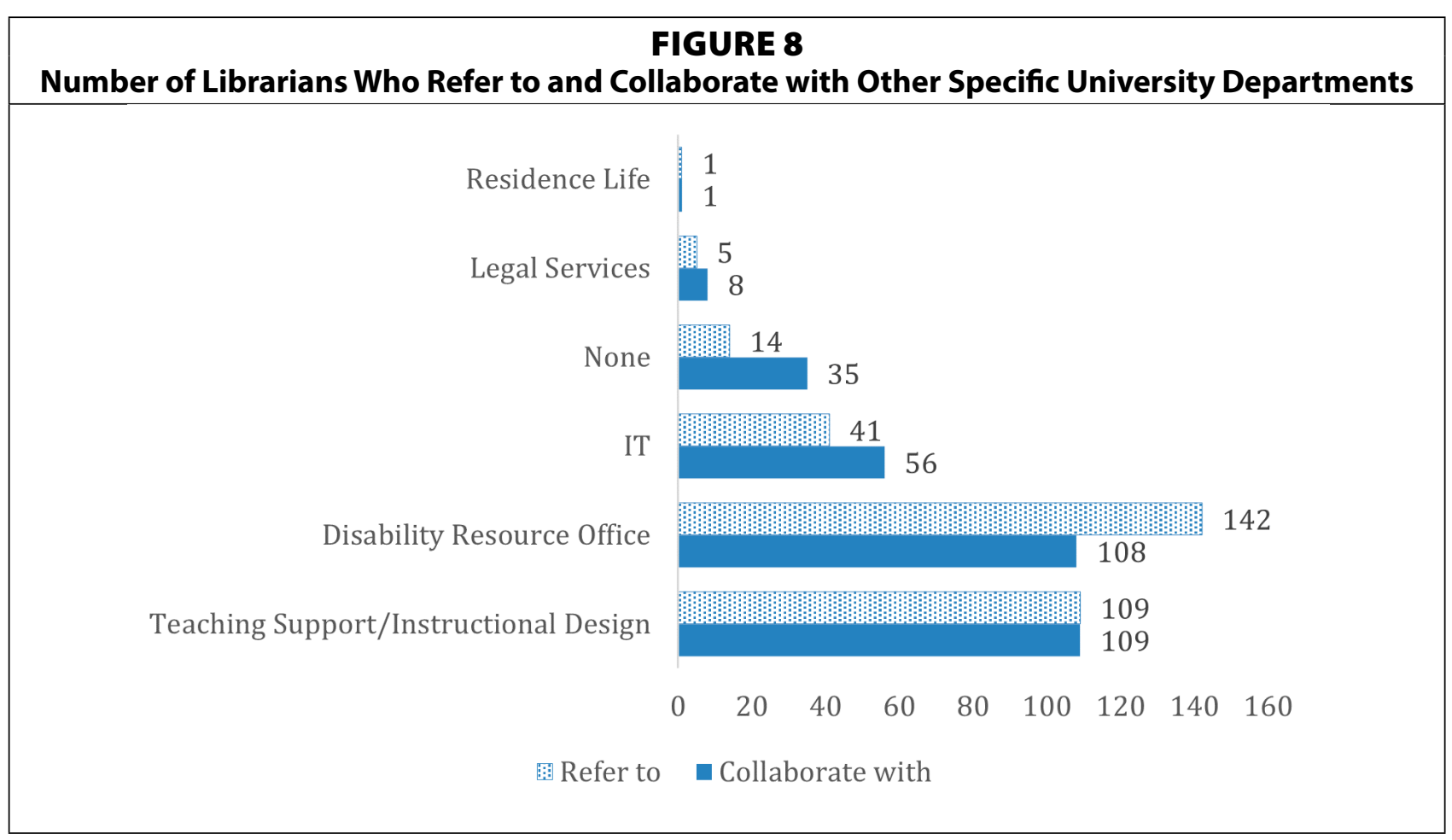




\section{Accessibility Support}

Most librarians rated the accessibility support they receive from their institution, library, and the overall profession as either OK or good, although the support provided by the institution received the most votes as good or excellent support (see figure 9). Librarians identified lack of inadequate staffing (154), lack of expertise (146), and issues with updating existing content (134) as the greatest challenges in making OERs accessible (see table 4).

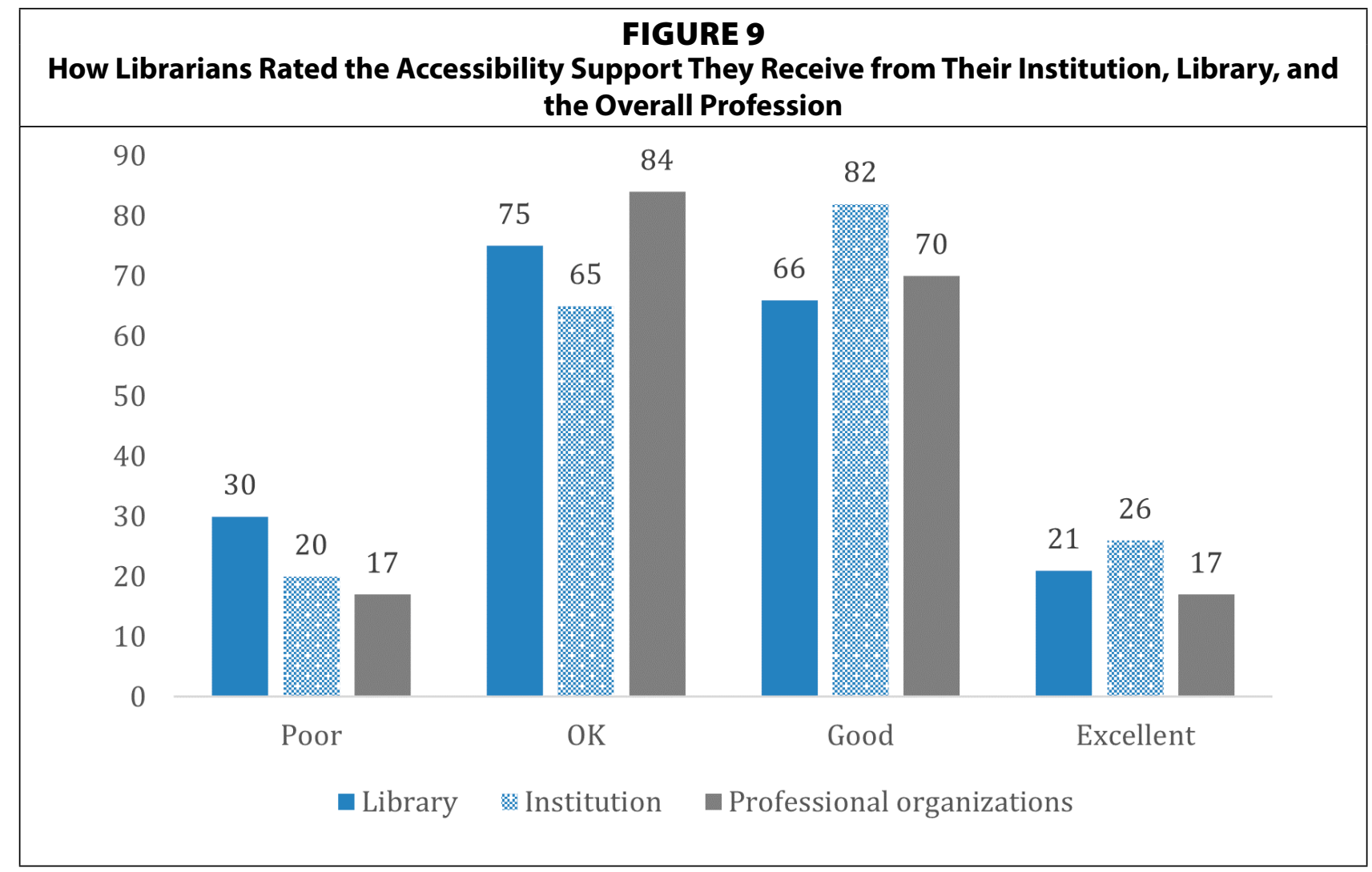

\begin{tabular}{|c|c|c|}
\hline \multicolumn{3}{|c|}{$\begin{array}{c}\text { TABLE } 4 \\
\begin{array}{c}\text { Number of Librarians Who Rated a Specific Issue as a Challenge or Major Challenge in } \\
\text { Making OERs Accessible }\end{array}\end{array}$} \\
\hline Type of Challenge & No. of Librarians & $\%$ of All Librarians \\
\hline Inadequate staffing & 154 & $80 \%$ \\
\hline Lack of expertise & 146 & $76 \%$ \\
\hline Difficulty addressing existing content & 134 & $69 \%$ \\
\hline Finances & 120 & $62 \%$ \\
\hline Lack of institutional guidance & 120 & $62 \%$ \\
\hline Product restrictions (authoring and hosting platforms and tools) & 112 & $58 \%$ \\
\hline Scaling up & 108 & $56 \%$ \\
\hline Lack of library guidance & 98 & $51 \%$ \\
\hline Low priority for institution & 84 & $44 \%$ \\
\hline Lack of available tools (such as JAWS, WAVE, Adobe) & 82 & $42 \%$ \\
\hline Low priority for library & 67 & $35 \%$ \\
\hline Lack of library community guidance & 64 & $33 \%$ \\
\hline
\end{tabular}


Most librarians said that easy-to-use tools (169), in-depth training (131), and community support to help troubleshoot issues (119) would be most helpful in ensuring OERs are accessible (see table 5).

TABLE 5

Number of Librarians Who Rated Specific Types of OER Accessibility Support Would Be Very Helpful

\begin{tabular}{|l|c|c|}
\hline Type of Support & No. of Librarians & \% of all Librarians \\
\hline Easy-to-use tools & 169 & $88 \%$ \\
\hline In-depth training & 131 & $68 \%$ \\
\hline Community support to troubleshoot issues & 119 & $62 \%$ \\
\hline More funding & 110 & $57 \%$ \\
\hline Webinars & 96 & $50 \%$ \\
\hline Conference sessions & 51 & $26 \%$ \\
\hline More staffing & 6 & $3 \%$ \\
\hline Born-accessible OERs & 3 & $2 \%$ \\
\hline
\end{tabular}

\section{Discussion}

\section{Librarian Accessibility Knowledge and Training}

This survey set out to serve as a baseline measure of where OER librarians stand when it comes to their perceived knowledge and practices of OERs. The results of this survey indicate that most librarians who routinely work with OERs possess, by their own measure, a basic understanding of web accessibility and that many apply this knowledge at least some of the time. Also, many have participated in some form of accessibility training. However, a small minority consider themselves accessibility experts who regularly work with accessibility tools and best practices. Because of the complexity involved in making OERs accessible, those who practice it sporadically will likely take even longer to do so and might not be aware of all that accessibility involves. The most common types of training librarians reported engaging in - one-off workshops, conference sessions, and webinars - suggest that professional development in this area is mostly informal and piecemeal, focused on more introductory concepts and practices. Accessibility is still an emerging area of focus for librarians, and more work needs to be done to bring these concerns to the fore.

\section{Working with Accessibility}

Considering that most librarians have not received in-depth training in accessibility, that just 15 librarians, or 8 percent, reported never considering accessibility when working with faculty to adapt and create OERs is encouraging. However, slightly fewer than half of librarians reported they always consider accessibility. The rest only sometimes consider it, and the survey did not measure how often or to what extent they do. Even fewer librarians said they consider accessibility when selecting OERs to include in their collections. While overall this can be seen as a positive starting point for a baseline measure, there is clearly room for improvement. The one bright spot were librarians from associate's colleges, the majority of whom said they do consider the accessibility of OERs in collection development decisions. Associate's colleges have shown to be early adopters and supporters of OERs partly because 
of the financial needs of their students. ${ }^{26}$ But it is perhaps surprising that research universities, with their greater resources, are not doing more to ensure OERs in their collections and those that their faculty use are accessible.

Most librarians also reported providing at least one service in support of accessibility and OERs; however, the most common services were more passive in nature, such as consultations or sharing information from other groups. Fewer than a third offer automatic or manual checks for accessibility, and just 15 percent do any accessibility remediation work. While that figure is close to the same number of librarians who provide publishing oversight of OERs, it is lower than the 24 percent of librarians who oversee an incentive fund. When a library takes an active role in the adaptation and creation of OERs, either through providing financial incentives to faculty or by providing publishing services, it is especially important to ensure the books and other materials they use for these grants are accessible to everyone. OERs that are born accessible help everyone, as they reduce the burden on other librarians and faculty to ensure that they are accessible. For those librarians who help remediate OERs, or who know that their faculty have remediated OERs, sharing these accessible versions with appropriate metadata to indicate that they are accessible could also benefit the wider community. As the majority of librarians indicated in the survey that their institution follows the WCAG AA standard, that can serve as a good goal to aim for when making OERs accessible.

At the same time, making OERs accessible takes time and resources that a library might not always have. What accessibility services a library provides, therefore, needs to be discussed, both within individual libraries and the broader profession. Ideally, all libraries will provide at least some basic support, such as helping faculty determine if an OER is accessible and providing guidance on how to make an OER accessible. This could include directing them to another place at their institution that can provide more active help. Responses from the survey indicate that the disability resource office (DRO) is the most common referral, although not as many collaborate with the DRO. Such collaborations could provide more support in this area to libraries and should therefore be explored.

\section{Challenges}

No matter what level of support libraries offer in this area, however, OER librarians will likely still face challenges. Librarians indicated that the biggest impediments to making all open education material within their purview accessible are a lack of adequate funding and support as well as a shortage of personnel with both the time and expertise necessary to scale up accessibility work. Although libraries and librarians are not the only entities and individuals within higher education responsible for accessibility, they are prominent proponents of OERs and the open education movement more generally. If OER adoption continues to gain traction at colleges and universities, accessibility cannot be ignored. This might be best addressed by the profession's involvement. Librarianship, as a whole, needs to advocate that more resources be put toward accessibility. Professional organizations can also develop and offer more robust professional development opportunities on accessibility, particularly resource evaluation, remediation, and the tools needed for both. Institutions need to also prioritize accessibility for OERs (preferably before students and other users issue complaints and start legal suits) by providing additional financial support and more robust training and guidance on creating and editing materials to be accessible. 
As stated before, ensuring that OERs are accessible is a huge undertaking. Evaluation and remediation are often resource-intensive and time-consuming processes. Yet the vast majority of the librarians surveyed spend less than a quarter of their time on OERs. Scaling up such support would only increase the strain currently placed upon OER librarians. Professional organizations and institutions ought to form strong partnerships, or work within existing consortia, to address these difficulties inherent in ramping up remediation of existing open education content. They need to consider the accessibility of the commonly used online platforms that house OERs, such as OpenStax and bepress, and the usability of tools needed to evaluate and remediate content. Professional organizations within the field of librarianship can advocate for accessibility in this context as well, pushing developers and vendors to address any issues with their products or helping to build new, open platforms and tools themselves.

\section{Recommendations}

Based on the findings of the survey, the authors recommend that:

- OER librarians focus on checking open textbooks for accessibility before adding them to their collections.

- OER librarians who help faculty select OERs, especially those whose libraries provide incentive funding to faculty, provide some level of assistance with evaluating textbooks for accessibility.

- OER incentive funds include accessibility as a requirement for any outputs.

- Libraries incorporate accessibility into their collection development policies, including for OERs.

- Libraries ensure they provide the financial resources necessary for OER initiatives to support accessibility.

- Libraries seek out campus collaborators, such as the disability resources center, that allow them to better support accessibility for OERs.

- Professional groups such as ACRL, SPARC, and the Association of Research Libraries provide more in-depth accessibility training and resources for OER librarians.

- Librarians and professional societies advocate for accessible platforms for OERs.

\section{Conclusion}

The OER movement often touts making education accessible to everyone; however, unless the movement also considers actual accessibility in the creation and adaptation of open textbooks and other material, a portion of learners will remain left without the benefit of OERs. This survey shows that some OER librarians are considering accessibility in their work, but not often enough. Training as well remains an issue. Accessibility is not a simple topic to learn, especially in practical terms of evaluating and creating material. Tools are known to be complex, and one-time sessions are unlikely to be enough to help a librarian be fully conversant in accessibility. All of this may change, however, if the profession as a whole begins to devote more attention to accessibility and other issues related to the inclusiveness of online learning.

While this survey does help set a baseline for measuring how OER librarians rate their perceived knowledge about accessibility and how they incorporate it into their work, it is limited in measuring how much they actually know. Although anyone in the world was welcome to take the survey, the vast majority of librarians who took it were from the United States, which means it is not able to measure the knowledge and activities of librarians from 
across the globe. The voluntary nature of the survey also means that self-selection could have been in play, as librarians who work with accessibility were more likely to take the survey.

Future studies could explore in further detail what struggles librarians face in making OERs accessible, how they incorporate accessibility into their work, what types of trainings best help librarians make OERs accessible, and ways to scale up accessibility for OERs. Future researchers could also develop a tool to assess librarians' actual knowledge of accessibility.

\section{Acknowledgments}

The authors would like to thank the Association of College and Research Libraries' Research and Scholarly Environment Committee for their grant that helped fund this project.

\section{Notes}

1. "Open Education," SPARC, accessed June 30, 2020, https://sparcopen.org/open-education/.

2. Maimoona Al Abri and Nada Dabbagh, "Open Educational Resources: A Literature Review," Journal of Mason Graduate Research 6, no. 1 (2018): 85-86, https://doi.org/10.13021/G8jmgr.v6i1.2386.

3. Al Abri and Dabbagh, "Open Educational Resources: A Literature Review," 92-93.

4. Serena Henderson and Nathaniel Ostashewski, "Barriers, Incentives, and Benefits of the Open Educational Resources (OER) Movement: An Exploration into Instructor Perspectives," First Monday (December 1, 2018), https://doi.org/10.5210/fm.v23i12.9172.

5. Americans with Disabilities Act of 1990, Pub. L. No. 101-336, § 12101 (1990).

6. World Wide Web Consortium, "Introduction to Web Accessibility," Web Accessibility Initiative (WAI), accessed June 30, 2020, https://www.w3.org/WAI/fundamentals/accessibility-intro/.

7. Americans with Disabilities Act of 1990.

8. Lindsay McKenzie, "Fifty Colleges Sued in Barrage of ADA Lawsuits over Web Accessibility," Inside Higher Ed (2018), https://www.insidehighered.com/news/2018/12/10/fifty-colleges-sued-barrage-ada-lawsuits-over-webaccessibility.

9. World Wide Web Consortium, "Web Content Accessibility Guidelines (WCAG) Overview," Web Accessibility Initiative (WAI), accessed June 30, 2020, https://www.w3.org/WAI/standards-guidelines/wcag/.

10. Lindsay McKenzie, “Universities Still Struggle to Make Websites Accessible to All," Inside Higher Ed (November 6, 2018), https://www.insidehighered.com/news/2018/11/06/universities-still-struggle-make-websitesaccessible-all.

11. Mark Lieberman, “Technology Can Help Address Accessibility Challenges, but Many Say It's an Incomplete Solution," Inside Higher Ed, accessed June 30, 2020, https://www.insidehighered.com/digital-learning/ article/2018/05/02/technology-can-help-address-accessibility-challenges-many-say.

12. Adina Mulliken, "Eighteen Blind Library Users' Experiences with Library Websites and Search Tools in U.S. Academic Libraries: A Qualitative Study," College \& Research Libraries 80, no. 2 (2019): 152-68, https://doi. org/10.5860/crl.80.2.152.

13. Stephanie J. Adams, Corey Halaychik, and Jennifer Mezick, "Accessibility Compliance: One State, Two Approaches," Serials Librarian 74, no. 1/4 (January 2018): 163-69, https://doi.org/10.1080/0361526X.2018.1427963; Laura DeLancey and Kirsten Ostergaard, "Accessibility for Electronic Resources Librarians," Serials Librarian 71, no. 3/4 (November 16, 2016): 180-85, https://doi.org/10.1080/0361526X.2016.1254134; Michael Fernandez, “How Accessible Is Our Collection? Performing an E-Resources Accessibility Review," Serials Librarian 74, no. 1/4 (May 31, 2018): 81-86, https://doi.org/10.1080/0361526X.2018.1430424; Amy Kazuye Kimura, “Defining, Evaluating, and Achieving Accessible Library Resources: A Review of Theories and Methods," Reference Services Review 46, no. 3 (January 1, 2018): 425-38, https://doi.org/10.1108/RSR-03-2018-0040.

14. Rebeca Peacock and Amy Vecchione, "Accessibility Best Practices, Procedures, and Policies in Northwest United States Academic Libraries," Journal of Academic Librarianship 46, no. 1 (January 1, 2020): 3-4, https://doi. org/10.1016/j.acalib.2019.102095.

15. Peacock and Vecchione, "Accessibility Best Practices, Procedures, and Policies in Northwest United States Academic Libraries," 4.

16. Beth Ashmore, Jill E. Grogg, and Hannah Rosen, "An Accessibility Survey of Libraries: Results, Best Practices, and Next Steps," Serials Librarian 78, no. 1/4 (June 1, 2020): 215, https://doi.org/10.1080/0361526X.2020.1703496.

17. Ashmore, Grogg, and Rosen, “An Accessibility Survey of Libraries," 215-16. 
18. Ashmore, Grogg, and Rosen, "An Accessibility Survey of Libraries," 216.

19. N. Moreno, E.T. Caro, and R. Cabedo, "Systematic Review: OER and Disability," in 2018 IEEE 5th International Congress on Information Science and Technology (CiSt) (2018), 428-31, https://doi.org/10.1109/CIST.2018.8596659; Xiangling Zhang et al., "Accessibility within Open Educational Resources and Practices for Disabled Learners: A Systematic Literature Review," Smart Learning Environments 7, no. 1 (January 3, 2020): 1, https://doi.org/10.1186/ s40561-019-0113-2.

20. Veronica McGowan, "Institution Initiatives and Support Related to Faculty Development of Open Educational Resources and Alternative Textbooks," Open Learning: The Journal of Open, Distance and e-Learning 35, no. 1 (January 2, 2020): 24-45, https://doi.org/10.1080/02680513.2018.1562328.

21. Silvia Da Rosa and Regina Motz, "Do We Have Accessible OER Repositories?" in 2016 International Symposium on Computers in Education (SIIE) (2016), 2, https://doi.org/10.1109/SIIE.2016.7751867.

22. J. Puello, Y. Puerta, and L. Martínez, "Accessible Digital Repositories for Inclusive Education," International Journal of Applied Engineering Research 12, no. 14 (2017): 4407.

23. Puello, Puerta, and Martínez, "Accessible Digital Repositories for Inclusive Education," 4407-08.

24. Eulho Jung, Christine Bauer, and Allan Heaps, "Higher Education Faculty Perceptions of Open Textbook Adoption," International Review of Research in Open and Distributed Learning 18, no. 4 (June 16, 2017): 124, https:// doi.org/10.19173/irrodl.v18i4.3120.

25. Talea Anderson and C. Leachman, "Centering Accessibility: A Review of Institutional Repository Policy and Practice," Preprint, May 2020; Laura Waugh et al., "Accessibility in Institutional Repositories Survey 2019" (Texas Data Repository Dataverse, July 8, 2020), https://doi.org/10.18738/T8/LUGYPO.

26. Lisa Peet, "Academic Libraries Are Flexing to Meet the Needs of Nontraditional Students," Library Journal (2019), http://search.proquest.com/docview/2279792815?pq-origsite=summon. 